\title{
Metodologias feministas no ensino da comunicação: Um relato de experiência no curso de Publicidade e Propaganda.
}

\author{
BARRETO JANUÁRIO, Soraya ${ }^{1}$ \\ DANTAS, Marisa²
}

\section{Resumo}

O presente artigo visa relatar a experiência do processo de aplicabilidade de metodologias feministas associadas ao conceito de mídia tática no curso de Publicidade e Propaganda da UFPE. Historicamente 0 ideal de aprendizagem dos cursos de Publicidade no Brasil seguem o raciocínio imposto para o mercado, no qual estudo e aplicação da criatividade se concentra do consumo e do capital (OLIVEIRA, 2016). À luz das teorias feministas e de gênero como Haraway (1995), Butler (2008), Rubin (1992), propusemos como metodologias feministas (ADRIÃO, 2014) o ensino da mídia tática (GARCIA; LOVINK, 1997) a partir de técnicas para trabalhos com grupos (ADRIÃO, 2014; BARÓ, 1992; FREIRE, 1987) e recursos da arteterapia na graduação de comunicação. Desenvolvidas no contexto da crítica à neutralidade e ao positivismo nas ciências, as metodologias feministas são, de forma mais ampla, estratégias ou instrumentos de mudança social baseadas no ideal de equidade social de gênero (NEVES; NOGUEIRA, 2015) e também de raça, classe social e outros marcadores. Transgredindo a lógica hegemônica da comunicação social e de seu ensino, objetivamos promover um diálogo entre o conhecimento acadêmico e empírico dos movimentos sociais, na construção de uma comunicação social implicada politicamente. Em sala, metodologias participativas e dialógicas ancoradas em propostas como as de Paulo Freire (1987) e Martin Baró (1992), associadas aos recursos da arteterapia que visam o estímulo à criatividade e à expressão de si. Sob a forma de oficinas, discutimos e produzimos mídias historicamente utilizadas por movimentos sociais, tais como: fanzine, estêncil, detournement e memes. Pretendemos a subversão e o uso tático dessas mídias como forma de ampliar a visão sobre a propaganda e a comunicação social das/dos futuras/os publicitárias/os, e de promover um redirecionamento da criatividade e das vozes das/dos sujeitas/os que a produzem. Como resultados, apresentaremos o uso da mídia tática enquanto metodologia feminista na produção e ensino da atividade publicitária.

Metodologias feministas. Mídia tática. Publicidade. Comunicação. Gênero.

Feminist methodologies in the teaching of communication: An experience report in the course of publicity and advertising

\section{Abstract}

This article aims to report the experience of the applicability process of feminist methodologies associated to the concept of tactical media in the graduation course of

1 Doutora em Ciências da Comunicação. Publicitária, professora e pesquisadora no Departamento de Comunicação da Universidade Federal de Pernambuco. Coordenadora do OBMIDIA UFPE: Observatório de mídia: Gênero, Democracia e Direitos Humanos. Discute teorias feministas e de gênero, esportes, publicidade e comunicação.

2 Graduada em Publicidade e Propaganda pela UFPE. Mestranda no Programa de pós-graduação em Psicologia da UFPE e pesquisadora no LabESHU - Lab. de Estudos das Sexualidades, arteterapeuta em formação pela Traços. Discute teorias feministas e de gênero, sexualidades, movimentos sociais, redes sociais digitais e comunicação social. 
Metodologias feministas no ensino da comunicação: Um relato de experiência no curso de Publicidade e Propaganda.

Advertising and Propaganda of UFPE. Historically the ideal of learning of graduations in Advertising in Brazil follow the reasoning for the market, in which study and application of creativity concentrate consumption and capital (OLIVEIRA, 2016). In the light of feminist and gender theories such as Haraway (1995), Butler (2008), Rubin (1992), we proposed the teaching of tactical media (GARCIA; LOVINK, 1997) as feminist methodologies (ADRIÃO, 2014) work with groups (ADRIÃO, 2014; BARÓ, 1992; FREIRE, 1987) and art therapy resources in the graduation of communication. Developed in the context of the critique of neutrality and positivism in the sciences, feminist methodologies are, more broadly, strategies or instruments of social change based on the ideal of gender social equality (NEVES; NOGUEIRA, 2015) and also of race, social class and other markers. Transgressing the hegemonic logic of social communication and its teaching, we aim to promote a dialogue between the academic and empirical knowledge of social movements, in the construction of a politically involved social communication. In the classroom, participatory and dialogical methodologies anchored in proposals such as Paulo Freire (1987) and Martin Baró (1992), associated with the resources of art therapy aimed at stimulating creativity and self expression. In the form of workshops, we discuss and produce media historically used by social movements, such as: fanzine, stencil, detournement and memes. We intend to subversion and the tactical use of these media as a way to expand the vision of propaganda and the media of the future, and to promote a redirect of creativity and the voices of the subjects that the produce. As a result, we will introduce the use of tactical media while feminist methodology in the production and teaching of advertising activity.

Feminist methodologies. Tactical media. Advertising. Communication. Gender.

\section{Introdução}

Escrevemos esse texto para relatar nossa experiência no estágio de docência de Marisa Dantas na componente Comunicação e Gênero ofertada no curso de Publicidade e Propaganda da UFPE pela Profa. Dra. Soraya Barreto. Nesse relato, utilizaremos a primeira pessoa do singular e do plural, primeiramente porque ser o relato de nossa experiência. Depois, acreditamos ser válido que nos coloquemos na construção deste texto como dois "corpo-mulher inserido e atuante no universo acadêmico" (2018, p.35), subvertendo a lógica hierárquica academicamente estabelecida de orientadora e orientanda já que observamos 0 processo de ensino-aprendizagem como mútuo e flutuante. Se pretendemos mover estruturas que elas iniciem pelas nossas próprias produções. Para isso, notificaremos no texto sempre que utilizarmos a primeira pessoa do singular quando uma experiência vivida por só uma de nós for relatada.

A área publicitária é famosa na prática e uso de estereótipos que com alguma frequência fere aos direitos humanos (BARRETO JANUÁRIO, 2016) e, especialmente no Brasil, fere ainda mais os direito e representação das mulheres. $\mathrm{Eu}$, Soraya, tive uma formação fortemente voltada para o mercado e a manutenção das práticas implementadas no fazer publicitário. Os cursos de graduação em Publicidade e Propaganda propiciam a inclusão do discente numa gama de saberes mercadológicos, contudo, pouco humanista. 
Metodologias feministas no ensino da comunicação: Um relato de experiência no curso de Publicidade e Propaganda.

Quando adentrei como docente do curso de Publicidade e Propaganda da Universidade Federal de Pernambuco (UFPE) havendo trabalhado no mercado publicitário local e nacional ao longo de dez anos, e ainda, sendo militante feminista há mais de 15 anos, pude observar com mais atenção as práticas e discursos publicitários em relação à mulher e as questões de gênero. Contudo, sempre me questionei se essa manutenção de um ethos discursivo e imagético quanto ao lugar objetificado e hipersexualizado (MOTA-RIBEIRO, 2005) da mulher na publicidade não teria relação direta com as pedagogias (LOURO, 2004) e escolhas implementadas pelos cursos de Publicidade no país.

Em 2014, ofereci pela primeira vez a componente eletiva "Comunicação e Gênero" no curso de Publicidade e Propaganda da UFPE. O intuito era desenvolver o pensamento crítico do corpo discente com a proposta de compreender melhor as questões de gênero e direitos das mulheres, (re)conhecer as práticas abusivas a despeito das representações femininas na Publicidade através da leitura crítica da mídia (KELLNER; SHARE, 2008) e repensar os critérios de criação e veiculação no uso da objetificação dos corpos na encenação publicitária (VERÍSSIMO, 2008).

Após 3 anos focando numa leitura mais crítica do que estaria por trás dos critérios de produção e na efetiva veiculação publicitária na mídia, fui desafiada a impingir um novo olhar para o tema da disciplina. Em 2017 fui procurada pela minha ex-aluna e orientanda de graduação, Marisa Dantas, que gostaria de estar na componente Comunicação e Gênero como atividade do estágio-docência em seu mestrado no Programa de Pós-graduação em Psicologia da UFPE. A proposta era de reconstruirmos a disciplina, saindo do espaço analítico e crítico para a efetiva produção "publicitária" sob um novo olhar, o da mídia tática. Pensar o fazer publicitário por uma nova ótica e lógica de produção que dialoga não mais com o mercado, mas com os movimentos sociais, o feminismo, as metodologias participativas de trabalho com grupos e os recursos da arteterapia.

Em 2015, quando construímos a monografia que, eu, Marisa, vim a apresentar na conclusão da graduação em Publicidade e Propaganda quisemos estudar como os movimentos feministas comunicam suas pautas. Aprendemos muito sobre movimentos feministas e comunicação, culminando na apresentação do texto intitulado Análise comunicacional do movimento feminista: caso Marcha das Vadias Recife. Nesse trabalho, conseguimos observar algumas particularidades nas peças de propaganda feministas quando as comparava com a publicidade tradicional. Eu entendia, naquele momento, que as duas formas de comunicar - publicidade tradicional e propaganda dos movimentos sociais tinham funções diferentes pois serviam a fins, e algumas vezes a projetos políticos distintos. 
Nesse mesmo período, me dedicava a construir a Coletiva Feminista Diadorim - um grupo de mulheres não institucional com perspectivas antirracista, anticapitalista e interseccional. Em várias das reuniões, nos víamos com algum tipo de demanda da comunicação. Por vezes, escrever uma nota de apoio ou repúdio, divulgar uma manifestação, um seminário de formação e outros tipos de comunicação - internas e externas. Como semelhança, todas essas pautas na Diadorim e nos movimentos sociais parceiros tinham em comum o baixíssimo ou nenhum orçamento - tratava-se de um movimento social anticapitalista sem nenhum tipo de financiamento institucional. Ficava a questão sobre a dificuldade de pensar a comunicação do movimento social a partir dos caminhos que aprendi, o que me levou a refletir que o conteúdo da mensagem partia de ideais de sociedade diferentes dos que nortearam minha prática até ali.

\section{O uso tático da mídia como um fazer pedagógico}

Seguindo esse percurso, fiz uma oficina na Marco Zero Conteúdo sobre Ativismo Digital. Lá, foram apresentadas várias ferramentas, desde técnicas de segurança comunicacional a estratégias combativas na comunicação. Nesse curso, descobri a ideia de mídia tática. Um conjunto aberto de estratégias comunicacionais de resistência, usada em contextos políticos como o de ditaduras, que tem práticas e estética próprias (GARCIA; LOVINK, 1997).

O termo "mídia tática" se refere a uma utilização crítica e teorização das práticas de mídia que recorrem a todas às formas de mídias, antigas e novas, ambas lúcidas e sofisticadas, para a realização de diversos objetivos não comerciais, impulsionando todos os tipos de questões políticas potencialmente subversivas. (N5M, 1996)

Enquanto conceito começou a ser cunhado em 1997 por Geert Lovink e David Garcia no texto "O ABC da Mídia Tática", apoiados nas discussões da primeira edição do Next Five Minutes (N5M) - um festival de política, mídia, arte e ativismo ocorrido em Amsterdã em 1993. Diferente da imprensa alternativa, a mídia tática acontece quando artefatos do tipo "faça-você-mesmo" são usados por grupos ou pessoas "oprimidos ou excluídos de uma cultura dominante" (GARCIA; LOVINK, 1997). Essas práticas de mídia são localizadas, parciais e participantes ativas da construção histórica dos fatos. 
Metodologias feministas no ensino da comunicação: Um relato de experiência no curso de Publicidade e Propaganda.

Mídias táticas são o que acontece quando mídias baratas tipo 'faça você mesmo', tornadas possíveis pela revolução na eletrônica de consumo e formas expandidas de distribuição (do cabo de acesso público à internet), são utilizadas por grupos e indivíduos que se sentem oprimidos ou excluídos da cultura dominante. A mídia tática não apenas noticia eventos, porque elas nunca são imparciais, elas sempre participam e é isto que mais do que qualquer outra coisa as separa da mídia mainstream. (GARCIA; LOVINK, 1997, p. X)

Segundo Anne Clinio (2012), as alianças entre militantes táticos são frouxas e temporárias, essa ferramenta cria uma "zona de consenso temporária" (LOVINK GARCIA, 1999) que facilita a hibridização, a mutação. Nessa revisão conceitual, Clinio mostra que diversos autores como Richardson (2002) e o coletivo Critical Art Ensemble (CAE) concordam que a nomeação desse conceito contribui para 0 esvaziamento do termo e que estabelecer padrões do que seria ou não essa mídia tática impede a característica mais interessante dela: "sua inventividade, fluidez e mobilidade"(CLINIO, 2012 p. 173).

Essas práticas de mídia se forjam baseadas na ética do "faça-você-mesmo" (no inglês "do it yourself", DIY) e por isso valoriza a criatividade mais do que a especialização técnica (CLINIO, 2012). Também opera no campo simbólico, sequestrando sentidos com intervenções efêmeras e desconstruções de significados. Os grupos de mídia tática têm interesse na reapropriação da produção técnica da comunicação e na liberdade de expressão digital.

O que chamamos de mídia tática é, acima de tudo, um viés crítico do fazer da comunicação com a intenção de reorientar o olhar político. Paulo José Lara (2008) evidencia dois pontos na percepção da mídia tática como forma de ação política. O primeiro ponto é sobre as plataformas que o uso tático da mídia propõe, criadas a partir do sistema midiático e também voltada para a produção de canais independentes de comunicação. O segundo ponto fala da forma de utilização dessas plataformas, as inúmeras possibilidades de desvios, recombinações e metalinguagens que constituem a estética astuciosa, polimorfa, "tão poética quanto guerreira" (GARCIA; LOVINK, 1997, p. xx). As táticas de mídia são ao mesmo tempo plataformas e produtos.

Enquanto a mídia oficial, comercial, corporativa e hegemônica cumpre um papel estratégico, à tática confere-se uma outra lógica, fugidia, híbrida, volátil, nômade e móvel, que a diferencia dos esquemas montados segundo uma ordem mercadológica, 
Metodologias feministas no ensino da comunicação: Um relato de experiência no curso de Publicidade e Propaganda.

vinculada às conquistas permanentes e relativas a um exercício de poder. (LARA, 2008, p. 53)

Um conceito importante para a compreensão do conceito de mídia tática é a distinção que Michel de Certeau faz sobre o significado de tática e estratégia. Ao chamar de estratégias os gestos e procedimentos estruturados pelos detentores do poder como exército, governo e ciência, o autor argumenta que estratégia seria "o cálculo das relações de forças que se torna possível a partir do momento em que um sujeito de querer e poder pode ser isolado" (CERTEAU, 2013, p.93). Já as táticas seriam o contraponto desse entendimento, no qual o autor advoga que, em oposição as táticas seriam ações que "jogam com os mecanismos da disciplina e não se conformam com ela a não ser para alterá-los" (2013, p.94).

Ele complementa que os usos táticos seriam as "ações de apropriação e engano que desobedecem ao pré-estabelecido, truques engenhosos, astúcias de caçadores, mobilidades nas manobras, operações polimórficas, achados alegres, poéticos e bélicos", (2013, p.98). A reapropriação e ressiginificação desse termo de Certeau associado às mudanças e avanços do composto comunicacional e midiático ocorrido nos anos 70 com advento da internet (GARCIA; LOVINK, 1997) ajudam a refletir como seus usos poderiam ampliar as possibilidades de subversão de um cenário previamente estruturado, como é o caso da mídia de massa, se utilizando da criatividade e rebeldia para subverter a ordem dominante e política dando voz e espaço aos sujeitos oprimidos e lou excluídos da esfera midiática. Com efeito, a mídia tática dialoga com o midiativismo mesclando movimentos sociais, ação política e engajamento social.

A possibilidade de promover práticas de mídia úteis aos movimentos sociais e distantes do referencial mercadológico era um refresco à forma que havia aprendido na graduação. Pensar em mídia tática abriu um grande leque de possibilidades criativas dentro e fora do contexto digital e do ambiente tecnológico. Passei a questionar a comunicação social, as imbricações entre práticas de mídia, ativismo e arte ao passo que me encontrei com a epistemologia e as metodologias feministas, os estudos do campo psi sobre as técnicas participativas de trabalhos com grupos e a arteterapia.

\section{Educação e Comunicação pautadas numa epistemologia feminista}

Nos ancoramos para a escrita deste relato e para a composição de nossas práticas docentes no campo que vem sendo chamado de epistemologia feminista (HARAWAY, 1995; SARDENBERG, 2004). Dialogamos, portanto, com o pensamento de Donna Haraway (1995) ao criticar os valores positivistas e a 
Metodologias feministas no ensino da comunicação: Um relato de experiência no curso de Publicidade e Propaganda.

ciência que se propõe a galgar o status de verdade. Na epistemologia feminista, a validade do conhecimento está em ser parcial. Advogamos por escritas científicas e por práticas pedagógicas que se sabem políticas e por isso, localizam-se em sua parcialidade. Como alternativa epistemológica e metodológica Haraway (1995) propõe a objetividade corporificada, uma "objetividade feminista [que] significa, simplesmente, saberes localizados” (p. 18).

Há ainda a importância de nos situarmos no feminismo pós-estruturalista. $O$ pensamento pós-estrutural é anti-humanista e tem sua base na linguagem como um fenômeno social (NOGUEIRA, 2001). Dizer-se anti-humanista significa que abandonamos a ideia essencialista de indivíduos que tem características "por natureza". Somos construídas/os. O ser é produto da linguagem; as identidades e a realidade são discursivamente construídas. O que quer dizer que a linguagem é o foco da transformação, pessoal ou social e, como fenômeno, observamos o espaço linguístico partilhado pelas pessoas (idem).

A linguagem não é um sistema fixo acordado por todos, mas um espaço de disputa e relações de poder. A experiência pessoal ganha sentido e estrutura-se através da linguagem e está, potencialmente aberta para ser reconstruída. É pela linguagem que pensamos e construímos as experiências pessoais e coletivas e é por meio dela que propomos mudanças. Por isso, em nossas aulas são de extrema importância as disputas de significados, as construções de sentido e o compromisso de diluir ao máximo as relações de poder por meio da circulação da fala.

Desenvolvidas no contexto da crítica à neutralidade do positivismo nas ciências, as metodologias feministas são, de forma mais ampla, estratégias ou instrumentos de mudança social baseadas no ideal de equidade entre os sexos, refletindo assim variadas perspectivas e teorias feministas (NEVES; NOGUEIRA, 2015). Para a sala de aula, nos apoiamos nos estudos de Karla Galvão sobre a "perspectiva feminista de trabalho com grupos" (ADRIÃO, 2014, s/p). Alguns elementos para entender essa perspectiva são "as relações de diferenças e desigualdades, as relações de poder e as tensões micro e macro políticas." (idem)

Nesse olhar, as diferenças que carregamos entre nós, por si só não são problemas apenas quando constituem desigualdades. Apoiada em Joan Scott (2005) e Judith Butler (2003), Karla discute como as normas de gênero/sexo/sexualidade/desejo são reiteradas de forma a promover exclusões e desigualdades a partir da repetição parodística de relações de poder. Além disso, a partir de Spivak problematiza as tensões micro relacionais e macro políticas, questionando a voz do sujeito subalterno. Dessa forma, pares binários em desigualdades de classe, território, raça são pensados de maneira micro relacional e macro políticas. 
Metodologias feministas no ensino da comunicação: Um relato de experiência no curso de Publicidade e Propaganda.

A partir das reflexões sobre grupos, relações de poder e as experiências de mídia, decidimos por desenvolver uma metodologia de aulas que se baseou nas técnicas participativas de trabalho com grupos, rodas de diálogo e Oficinas de Mídia Tática. Tentamos imprimir na componente Comunicação e Gênero o olhar do uso tático da mídia e da perspectiva feminista de gênero. Assim, optamos por trazer atividades que provocassem o corpo discente a reconhecer em si as questões políticas que trazíamos. Afinal, entendemos que as questões de gênero (e tensões próximas como sexualidade, raça, território etc) estão em todas e todos nós e nas relações que traçamos.

Dessa forma, o fazer da comunicação toma mais um caráter além do político. O viés expressivo estava presente em todas as aulas, seja por meio das atividades de fala, seja através das modalidades de arte que foram propostas enquanto práticas de mídia. Assim, as aulas variaram entre técnicas de grupos que tinham como objetivo a circulação da fala, técnicas de construção de sentidos e oficinas práticas de détournement, estêncil, fanzine, memes, leitura crítica de mídia e serigrafia.

Se por um lado, a forma de pensar a comunicação durante o curso me levava majoritariamente a desenvolver minha criatividade para a lógica do mercado, do consumo e do capital sem o comprometimento político que agora me habita, usar a mídia tática, construí-la e incentivar sua produção por publicitários/as em formação me parece uma alternativa às formas de praticar e ensinar a comunicação social.

Mais do que incentivar as/os alunas/os a terem um olhar crítico da mídia no tocante às questões feministas e de gênero (e aqui, amplio para outros debates consonantes com o propósito da justiça social como as questões de classe, raça, descolonialidade, sexualidade e tantos outros temas que podem ser lidos como subversivos ou contra-hegemônicos), o uso do que chamamos mídia tática como instrumento sugere que possamos cooperar com o empoderamento de comunicadoras/es capazes de subverter taticamente a mídia hegemônica e usar seus conhecimentos técnicos da comunicação social, da publicidade e da propaganda na produção de mídia alinhados/as à perspectiva política feminista, que de forma interseccional combate diversas formas de desigualdades.

$\mathrm{Na}$ tentativa de aplicar o que chamei de metodologia feminista por meio do ensino da mídia tática na graduação de comunicação, me questionei o que seria, na prática esse encontro de teorias. A partir de pensar taticamente as mídias, uma nova gama de possibilidades surge - bem diferentes dos que já estavam propostas. Se os movimentos sociais historicamente já utilizam meios como fanzines e rádios piratas, e mais atualmente a cultura hacker e as redes sociais digitais - o uso tático dessas mídias por pessoas que dominam a técnica da 
Metodologias feministas no ensino da comunicação: Um relato de experiência no curso de Publicidade e Propaganda.

comunicação não só pode ajudar a atualizar a eficácia da mensagem, como promove um redirecionamento da criatividade das/dos sujeitas/os que a produzem.

A partir de metodologias feministas para o trabalho com grupos (ADRIÃO, 2014) alinhadas à perspectiva parcial da produção de conhecimento técnico e científico no campo da comunicação, as possibilidades de atividades com o grupo passam desde pensar campanhas para causa feminista a produção de materiais gráficos como fanzine, estêncil entre outros. Mas, para além de incentivar a confecção de peças de comunicação sobre a temática feminista, interessa-me propor questionarmos o fazer da comunicação social desde seu teor criativo até suas práticas e estéticas a partir do feminismo.

Vislumbrando como enfoque metodológico que chamamos de metodologias feministas (ADRIÃO, 2014). O enfoque se deu em metodologias participativas e dialógicas ancoradas em propostas como as de Paulo Freire (1987) e Martin Baró (1992), que trataremos a seguir, associadas aos recursos da arteterapia que visam o estímulo à criatividade e à expressão de si. Sob a forma de oficinas, discutimos e produzimos mídias historicamente utilizadas por movimentos sociais

Com efeito, configura-se aqui o recorte que objetivamos: a promoção de um novo fazer publicitário que subverte a lógica tradicional no mercado propondo uma nova forma de fazer comunicação. Nesse âmbito, faremos um relato de experiência da implementação e debate de um tema de relevância para os Direitos Humanos experimentado numa área de saber que historicamente reforça e reitera a ótica do capital, perpetuando desigualdades. Dessa forma, pretende-se por meio desse trabalho descrever um relato de experiência das docentes - professora responsável e estágiária à docência - na implementação de um novo fazer pedagógico na Publicidade.

\section{Metodologias feministas: um experimento na publicidade}

Ao vislumbrar as diretrizes educacionais que regem as universidades públicas no Brasil, nos parece ser cada vez mais consensual, ou pelo menos cada vez mais amplamente divulgado, que o norteamento da educação brasileira passa - ou deveria passar - da ação educativa universitária dos saberes práticos da profissão e a preparação para o exercício da cidadania e a formação de uma conduta ética e solidária. Nos discursos pedagógicos há uma ênfase recorrente na necessidade de iniciação de jovens no campo de práticas e conhecimentos relativos aos valores públicos vinculados à democracia e aos direitos humanos. É exemplo, as Diretrizes e os Parâmetros Curriculares Nacionais (1998). No entanto, faz-se necessário reconhecer que a aceitação e implementação dessa meta como principal diretriz educacional tem sido mais retórica do que prática. 
Nesse sentido, estruturamos o calendário de aulas distribuindo as temáticas sobre questões de gênero, sexualidade e feminismos já trabalhadas na ementa da componente aquando criada em 2014. Associadas a essas temáticas estabelecemos um tipo de metodologia feminista (ADRIÃO, 2014) principal embasada nos pressupostos da mídia tática a serem utilizadas e levamos para 0 debate e ajustes finais a serem tratados com alunas e alunos no primeiro dia de aula. O debate acerca do plano de ensino da componente e suas metodologias foi alvo de questionamentos, tensionamentos e debates. Dialogando com a ementa previamente construída na época da primeira oferta da componente, com a proposta de Marisa no uso das metodologias feministas e mídia tática e , por fim, com alunas e alunos da componente no primeiro encontro do semestre, chegamos ao seguinte resultado:

Tabela 1. Distribuição de conteúdos e metodologias

\begin{tabular}{|l|l|}
\hline 1 & Apresentação da ementa e debate sobre a construção da disciplina. \\
\hline 2 & Construção e historicidade do conceito de Gênero \\
\hline 3 & Feminismo: história, movimento social e conquistas \\
\hline 4 & Diferentes formas de ser feminista + OFICINA Detournement \\
\hline 6 & Masculinidades - Filme The mask you live in (Netflix) \\
\hline 7 & Identidades de gênero + OFICINA de Leitura crítica da mídia (OBMIDIA UFPE) \\
\hline 8 & $\begin{array}{l}\text { Oficina sobre sexualidades + Oficina de Fanzine com Ana Catarina Moreira e Jucinara } \\
\text { Rodrigues }\end{array}$ \\
\hline 9 & Roda de diálogo sobre Feminismo negro e militância com Dandara Oniilari \\
\hline 10 & Cyberfeminismo + OFICINA de Memes \\
\hline 11 & Oficina de serigrafia em conjunto com o OBMIDIA UFPE \\
\hline 12 & Políticas Queer \\
\hline
\end{tabular}

O primeiro conteúdo debatido foi a construção e historicidade do conceito de gênero. Utilizamos uma técnica participativa de apresentação na qual cada pessoa dizia seu nome e uma palavra sobre como estava se sentindo. Depois de palavras de animação e curiosidade, formamos um círculo com o intuito de estabelecer uma multidirecionamento de fala e vozes. Para trazer o tema da aula, utilizamos a "caixa dos sentidos", entendendo que as palavras são territórios 
Metodologias feministas no ensino da comunicação: Um relato de experiência no curso de Publicidade e Propaganda.

politicamente em disputa e especialmente no debate sobre gênero, as polissemias são de extrema importância.

Várias palavras escritas em cartões coloridos, passaram de mão em mão numa caixa. As pessoas deveriam tirar uma palavra e dizer "o que acha que é", assim, vamos construindo os sentidos dos termos/conceitos. As palavras foram: construção social, feminismo, gênero, sororidade, machismo, trans/cis, queer, construção social, sexo, orientação sexual, homofobia/lesbofobia/bifobia, transfobia, misoginia, ciberativismo, sexualidades dissidentes, interseccionalidade, poder, opressão, masculinidades/feminilidades, heteronormatividade. Falamos bastante sobre construcionismo social e como a realidade é discursivamente construída, dando ênfase no uso da linguagem e das palavras. A turma parecia animada e algumas pessoas narraram fatos de suas vidas nos quais a linguagem teve papel central.

No terceiro encontro propomos uma aula expositiva utilizando como referência os silenciamentos e apagamentos históricos da mulher ao longo da construção de sociedade que vivemos hoje. Pedimos às alunas e alunos que trouxessem personagens históricos que foram apagadas dos escritos historicamente construídos e que agora ressurgem mediante o agendamento midiático do tema empoderamento e participação feminina. Entendemos por agendamento midiático a existência de interesses na promoção de determinadas ocorrências/notícias/produtos de consumo ou em evitar que essas pautas se tornem acontecimentos públicos (MOLOTCH; LESTER, 1999).

O quarto encontro foi sobre as diferentes formas de ser feminista, desde as práticas de ativismo às diferenças entre as vertentes feministas. $O$ debate foi feito a partir de textos de blogs feministas de variadas vertentes. Fizemos um abarcado geral sobre as nuances e problematizações entre os feminismos contando com a contribuição de diferentes vozes e partimos para a oficina de détournement. Essa é uma prática que tem por intenção sequestrar o sentido de uma publicidade, transformando a mensagem. Explicamos que a oficina era uma atividade expressiva e não avaliativa e a turma gostou da ideia. Rapidamente, tomaram toda a sala pelo chão e carteiras e dividiram o material disponível. Todas as pessoas produziram, algumas a partir das publicidades de revista disponíveis na mesa, outras a partir de notícias e de material publicitário que já tinham interesse. A turma captou logo a ideia do detournement e, entre pinceladas agressivas, colagens e palavras fortes, as produções fora tomando forma: anticapitalista. A atividade permitiu que a turma expressasse a insatisfação com as marcas que usavam do sexismo como argumento publicitário e com as reportagens de cunho machista. Logo após eles e elas decidiram compartilhar seus feitos com a turma, narrando brevemente o processo de produção. Um grupo de meninas citou que a 
Metodologias feministas no ensino da comunicação: Um relato de experiência no curso de Publicidade e Propaganda.

atividade havia sido bastante mobilizadora e que seus resultados não deveriam ficar restritos à sala de aula, perguntando se podiam colar aquilo nos corredores do Centro de Artes e Comunicação.

No encontro sobre masculinidades, objetivamos usar mídia como suporte educativo. Pautadas na corrente da educomunicação (SHAUN, 2002) como um espaço interdiscursivo, um campo de intervenção social, atuando nos territórios da educação e da comunicação, levando em conta as relações entre o sujeito social e as mídias, propomos o debate do documentário The Mask you live in, que reflete sobre as amarras, angústias e privilégios das masculinidades para debater o tema. Nessa aula, os homens da turma se colocaram mais do que nas outras e colocaram que finalmente.

No sexto encontro debatemos as identidades de gênero e como elas são retratadas e reiteradas pela mídia de massa usando exemplos de peças jornalísticas e publicitárias. Conduzimos uma oficina de leitura crítica da mídia, Ramonet (2003) advoga que existe uma força cívica cidadã que se opõe a certas estratégias da mídia de massa dominante, com a função preponderante de denunciar discursos e representações abusivas aos direitos humanos dos grandes grupos midiáticos, cúmplices e difusores da globalização liberal. $O$ autor propõe a leitura crítica da mídia como um mecanismo social para o controle da mídia. É pertinente refletir como consumimos os conteúdos produzidos pela mídia dominante, ler criticamente a mídia significada analisar criteriosamente seus parâmetros de produção, critérios discursivos, quem financia a mensagem e de onde ela parte. Isto é, pensar numa "sociedade (que) se mobiliza para ler mais criticamente a mídia, para consumir informações de forma mais criteriosa e preocupada" (CHRISTOFOLETTI; MOTTA, 2008, p.12).

A aula de número sete foi sobre o conceito de mídia tática. Discutimos sobre o tema com base em imagens projetadas na parede. O corpo discente se mostrou interessado durante o debate apesar de um tanto ansioso para a oficina. Questionaram bastante sobre a legalidade, consensuando que as leis também são políticas e as proibições de determinadas formas de mídia e expressão são interessantes aos grupos poderosos por silenciarem populações oprimidas, garantindo a manutenção das desigualdades. Levamos placas de raio-x, estiletes e marcadores e explicamos de forma simples a técnica de cortar da placa o que vai ser impresso deixando "pontes" entre os cortes. A oficina não teve temática específica, nos baseamos nas sensações que a discussão havia causado. Todas as pessoas fizeram com bastante interesse a partir de suas próprias histórias. Entre desenhos fortes e frases destacamos "I am not your negro", "Na cidade também tem índio", "Minha dor importa" e "Ser bicha é top" feitos por pessoas que carregavam em seus corpos os marcadores referenciados nas frases. 
Metodologias feministas no ensino da comunicação: Um relato de experiência no curso de Publicidade e Propaganda.

No oitavo encontro com o intuito de dinamizar e potencializar a produção de peças comunicacionais que fomentem a ideia da mídia tática propomos a realização de oficina de fanzines com a oficina sobre Sexualidades, facilitada pelas psicólogas Ana Catarina Moreira e Jucinara Rodrigues. Os fanzines são produções artesanais utilizadas para veicular informações sobre quaisquer assunto de gosto pessoal do autor ou de cunho político, social, reivindicativo. Caracterizados principalmente por seu caráter autoral, que valorizam a criatividade e a temática a ser trabalhada. Segundo Pinto (2013) "o mais importante neste processo é a personalidade dada à publicação, única e autoral” (2013, p.12). A produção realizada deveria pôr em práticas os assuntos tratados durante a oficina de sexualidades.

No nono encontro realizamos uma roda de conversa com Dandara Oniilari, militante feminista negra, psicóloga e pesquisadora. O método utilizado de roda de conversa funciona através de atos de fala, que ao ser produzido por uma pessoa instiga outra a falar, tornando possível se posicionar e ouvir os posicionamentos dos outros (MÉLLO et al., 2007), constituindo um espaço onde as pessoas reflitam sobre o cotidiano, suas relações com o trabalho, com o projeto de vida, com o mundo (AFONSO; ABADE, 2008).

$O$ décimo encontro foi pensado nos debates feministas no meio digital. $O$ tema da aula era o ciberfeminismo, termo cunhado na lógico do debate, reflexão e participação de agentes sociais feministas na internet e redes sociais. Propusemos para a prática do tema uma oficina de memes. Um meme pode ser entendido como "qualquer unidade de imitação e de transmissão cultural[...] propagando-se como imitação. Podem-se incluir as próprias linguagens humanas, as teorias científicas, as ideologias políticas, as crenças, as religiões etc."(ANDRAUS, 2005, p. 3).

A oficina de serigrafia foi um momento esperado pela turma durante todo 0 semestre. O Observatório de Mídia e Direitos Humanos da UFPE colaborou com três telas de serigrafia para que a oficina acontecesse e a turma levou camisas, bolsas e tecidos para que fossem estampados. A frase A mídia é deles mas a rua é nossa havia sido comentada na aula sobre Mídia tática, na intenção de expressar que apesar de a mídia hegemônica ter seus conglomerados que a comandam, potentes formas de mídia surgem das ruas. O processo de impressão da serigrafia foi compartilhado pela turma, que ficou encantada com o resultado nas camisas. Nesse dia, o clima era de confraternização e várias pessoas saíram já vestindo suas camisas.

Nosso último encontro com conteúdo foi sobre Políticas Queer. O termo que gerou tensões e curiosidades ao longo do semestre foi discutido a partir de trechos escritos e do vídeo Examined Life de Judith Butler e Sunaura Taylor. No 
vídeo, as duas debatem sobre uso do corpo e acesso à cidade e em paralelo aos trechos lidos, discutimos o que seria o tal Queer e como garantir acessos e dirimir discriminações às pessoas. Após, fizemos uma rodada da técnica "Que bom, Que pena, Que tal" na qual as pessoas completam as frases com elogios, críticas e sugestões, respectivamente. Essa atividade de avaliação foi utilizada quinzenalmente e foi a partir dela que balizamos a continuidade das aulas.

\section{Considerações finais}

A componente "Comunicação e Gênero", como zona autônoma e temporária, se reflete num padrão subversivo implementado num ambiente hostil aos debates que escapam à lógica neoliberal e mercadológica, de uma publicidade que esvazia o sentido político ideológico dos feminismos. Ao mesmo tempo que podemos vislumbrar um despertar de novas possibilidades metodológicas no fazer publicitário e comunicacional, a mídia tática revela em sua práxis, uma subjetividade combativa, transgressora. Ao repensarmos a comunicação e a mídia "enquanto nova forma de organização das formas de conflito e cooperação e afirmação da liberdade do "receptor" (CLINIO, 2013, p. 184) de mensagens como "produtor" de significados outros, alheios a sua concepção original" conferimos uma pluralidade de saberes e uma multidirecionalidade de produções.

Os resultados da inclusão de uma nova metodologia de ensinoaprendizagem pautados no pensamento feminista e na mídia tática mostraram que os objetivos da componente foram alcançados. É possível pensar e produzir uma comunicação combativa e transgressora a partir da sensibilização das/dos sujeitos para com as questões da justiça social e dos direitos humanos. Além da percepção positiva sobre as metodologias empregadas no ensino para o discente de publicidade, as produções ultrapassaram os muros da universidade com a reprodução de estêncil nas ruas da cidade, produção de camisetas e ecobags para os movimentos sociais e a produção e veiculação de memes com fins políticos distribuídos e veiculados entre as/os estudantes e suas redes.

A avaliação final da componente foi a produção de material de mídia para alguma causa ou grupo ativista e um relato pessoal de cada estudante avaliando seu processo de aprendizagem e a matéria. Esses relatos nos deixaram satisfeitas e felizes com o resultado. Terminamos com o trecho de um dos relatos, feitos por um estudante:

"Longe da internet, as aulas de Comunicação e gênero foram meu primeiro local de discussão sobre certos pontos. A escola não consegue falar sobre gênero, a família também não. Nosso contato 
Metodologias feministas no ensino da comunicação: Um relato de experiência no curso de Publicidade e Propaganda.

com certas temáticas acontece dentro dentro de uma bolha digital, mas apenas quando a bolha permite o contato. A metodologia da disciplina permitiu, principalmente, liberdade de expressão. Uma das questões que achei mais interessante foi a regra de que qualquer ideia poderia ser colocada em aula, mesmo que fosse discutível. A discussão aconteceu porque todos puderam falar. (...) A maior contribuição que, profissionalmente, estudar Comunicação e gênero me deu foi a de perceber que eu posso fazer publicidade a partir de alternativas que não são geralmente utilizadas por criadores de conteúdo e de campanhas. (...) Pessoalmente, me fez perceber meu corpo na sociedade como um objeto de manifestação, que precisa agir e não ficar inerte às injustiças (...)."

\section{Referências}

ADRIÃO, Karla Galvão. Perspectivas feministas na interface com o processo de pesquisa-Intervenção-pesquisa com grupos no campo Psi. labrys, études féministes/estudos feministas - julho/dezembro, 2014.

ANDRAUS, G. O Meme nas Histórias em Quadrinhos. Trabalho apresentado no NP16 Histórias em Quadrinhos durante o XXVIII Congresso Brasileiro de Ciências da Comunicação, Rio de Janeiro, RJ, 05-09, setembro, 2005. Disponível em: http://www.intercom.org.br/papers/nacionais/2005/resumos/R1279-1.pdf

BARRETO JANUÁRIO, Soraya. Masculinidades em (re)construção: gênero, corpo e publicidade. Covilhã: Coleção: Livros LabCom, 2016.

BUTLER, Judith. Problemas de gênero: Feminismo e subversão da identidade. Rio de Janeiro: Civilização Brasileira, 2003.

CERTEAU, Michel de. A invenção do cotidiano. São Paulo: Editora Vozes, 1994.

CHRISTOFOLETTI, R.; MOTTA, L.G. (Orgs.). Observatórios de mídia: olhares da cidadania. São Paulo: Paulus, 2008.

CLINIO, Anne. A ação política no cotidiano: a mídia tática como conceito operacional para pesquisas em mídia, cotidiano e política.

Revista_Mídia_e_Cotidiano, v. 1, n. 1, p. 169-188, 2012.

FREIRE, P. Pedagogia do Oprimido, Rio de Janeiro: Paz e Terra. 1987.

GARCIA, David; LOVINK, Geert. O ABC da mídia tática. Rizoma: intervenção. Disponível em:< http://www. rizoma. net/interna. php, 1997.

HARAWAY, D. Saberes Localizados: a questão da ciência para o feminismo e o privilégio da perspectiva parcial. In: Cadernos Pagu (5), p. 07-41. 1995.

KELLNER, D. SHARE, J. Educação para a leitura crítica da mídia, democracia radical e a reconstrução da educação. Educação e Sociedade, v. 29, n.104, p. 687-715, Campinas-SP: E. Cortez, CEDES, 2008.

LARA, Paulo José Olivier Moreira. Fragmentos das táticas da cultura: técnica e política dos usos de mídia, Dissertação de mestrado em Sociologia. São Paulo: Unicamp, 2008. Disponível em <http://libdigi.unicamp.br/document/?code=000468151>

LOURO, G. L. Um corpo estranho: ensaios sobre sexualidade e teoria queer. Belo 
Horizonte: Autêntica. 2004.

LOURO, Guacira Lopes. Teoria queer-uma política pós-identitária para a educação. Estudos feministas, 9.2: 541, 2001.

MCCARTHY, J.; GALVÃO, K. Projeto Artpad: um recurso para teatro, participação e desenvolvimento. [S. I.]: Centre for applied theatre research. 2001.

MOLOTCH, H. e LESTER, M. As notícias como procedimento intencional: acerca do uso estratégico dos acontecimentos de rotina, acidentes e escândalos. In: Nelson TRAQUINA (org.), Jornalismo: questões, teorias e "estórias", Lisboa, Veja, p. 34-51. 1999.

MOTA-RIBEIRO, S. Retratos de mulher: construções sociais e representações visuais do feminino. Porto: Campo das letras. 2005.

NARVAZ, M.; KOLLER, S. H. Metodologias feministas e Estudos de Gênero:

articulando pesquisa, clínica e política. Psicologia em Estudo, vol. 11, nº 3, Maringá, 2006, pp.647-654.

NEVES, S. e NOGUEIRA, C. Metodologias feministas: a reflexividade ao serviço da investigação nas ciências sociais. Psicologia: reflexão e crítica, 18(3), pp408-412. 2005.

NOGUEIRA, Conceição. Análise do discurso. 2001.

PINTO, R. D. Fanzine na Educação: algumas experiências em sala de aula. João Pessoa: Marca de Fantasia, 2013.

SANTOS, E. R. Pensamentos feministas: reflexões sobre propostas político teóricometodológicas descoloniais. pp 35-43, 2018.

SARDENBERG, C. M. B. Da Crítica Feminista à Ciência a uma Ciência Feminista? In: COSTA, A.A. e SARDENBERG, C.M.B. (orgs.) Feminismo, Ciência e Tecnologia. Universidade Federal da Bahia, vol.8. Coleção Bahianas, Salvador: REDOR, 2002.

SCHAUN, A. Educomunicação: reflexões e princípios. Rio de Janeiro: Mauad, 2002.

SCOTT, J. O enigma da igualdade. Estudos Feministas, Florianópolis, 13(1): 216, janeiro-abril. 2005.

SPIVAK, G. Pode o Subalterno falar? Ed UFMG: Belo Horizonte. 2010.

VERÍSSIMO, J. O corpo na publicidade. Lisboa: Colibri. 2008. 